\title{
Produção de Zínnia elegans em substratos a base de bagana de carnaúba
}

O cultivo de flores com o passar dos anos tem crescido e ganhado espaço no mercado agrícola. Objetivou-se avaliar o desenvolvimento da produção de mudas de Zínnia elegans Jacq., em substratos a base de bagana de carnaúba (BC) (Copernicia prunifera) no município de Chapadinha/MA. O experimento foi realizado no período de abril a junho de 2019 em casa de vegetação com controle de luminosidade 70\%, no Centro de Ciências Agrárias e Ambientais (CCAA) da Universidade Federal do Maranhão (UFMA). Foi conduzido em delineamento inteiramente casualizado, com 5 tratamentos de substratos formulados a base de bagana de carnaúba nas proporções de 0, 20,40,60, 80 e 100\% de BC acrescido de solo. Com substrato obtido a partir de bagana de carnaúba misturado ao solo (Latossolo Amarelo distrófico) a obtenção do desenvolvimento da espécie até o momento da floração, obtendo uma melhor qualidade. $\mathrm{O}$ substrato alternativo proporcionou melhoria na altura da planta com $(57,19 \%$ de $B C)$, volume radicular $(70,92 \%$ de BC), massa fresca radicular com $(66,81 \%$ de $B C)$ e massa fresca parte aérea com uma proporção de $(59,33 \%$ de BC). É recomendado o uso de $40 \%$ BC e $60 \%$ de solo como substrato para produção de zínia.

Palavras-chave: Planta ornamental; Produção orgânica; Floricultura.

\section{Production of Zínnia elegans in substrates based on carnaúba bagana}

\begin{abstract}
The cultivation of flowers over the years has grown and gained space in the agricultural market. The objective was to evaluate the development of the production of seedlings of Zínnia elegans Jacq., In substrates based on carnauba bagana (Copernicia prunifera) in the municipality of Chapadinha/MA. The experiment was carried out from April to June 2019 in a greenhouse with 70\% brightness control, at the Center for Agricultural and Environmental Sciences (CCAA) of the Federal University of Maranhão (UFMA). It was conducted in a completely randomized design, with 5 substrate treatments formulated based on carnauba bagana in the proportions of $0,20,40,60,80$ and $100 \%$ plus soil. With substrate obtained from carnauba bagana mixed with the soil (Dystrophic Yellow Latosol), obtaining the development of the species until the moment of flowering, obtaining a better quality. The alternative substrate provided an improvement in plant height with $(57.19 \% \mathrm{BC})$, root volume $(70.92 \% \mathrm{BC})$, root fresh mass with $(66.81 \% \mathrm{BC})$ and fresh aerial part with a proportion $(59.33 \%$ of $\mathrm{BC})$. It is recommended to use $40 \% \mathrm{BC}$ and $60 \%$ soil as a substrate for zinnia production.
\end{abstract}

Keywords: Ornamental plant; Organic production; Floriculture.

\section{Topic: Agroecologia}

Reviewed anonymously in the process of blind peer.
Received: 02/12/2020

Approved: $23 / 12 / 2020$
Vanessa Brito Barroso (D)

Universidade Federal do Maranhão, Brasil http://lattes.cnpq.br/6848925247182712 http://orcid.org/0000-0002-6675-5110 vanessaflick@hotmail.com

\section{Maurivan Barbosa Pachêco (iD)}

Universidade Federal do Maranhão, Brasil http://lattes.cnpq.br/2593810903242525 http://orcid.org/0000-0002-6146-9932 ivanbpacheco@hotmail.com

\section{Lídia Ferreira Moraes (iD}

Universidade Federal do Maranhão, Brasil http://lattes.cnpq.br/1998856441237863 http://orcid.org/0000-0002-5340-3263 lidiaferreira147@gmail.com

\section{Monik Silva de Moura (D) \\ Universidade Federal do Maranhão, Brasil http://lattes.cnpq.br/6534516032649253 http://orcid.org/0000-0002-9830-3557 monikmoura19@gmail.com \\ Ramón Yuri Ferreira Pereira (iD) \\ Universidade Federal do Maranhão, Brasil http://lattes.cnpq.br/0329684161084943 http://orcid.org/0000-0001-7600-1868 ramonyuri00@outlook.com \\ Aldenice Oliveira Conceição (iD) Universidade Federal do Maranhão, Brasil http://lattes.cnpq.br/3460543155460811 http://orcid.org/0000-0003-4945-3724} aldeniceagro@gmail.com

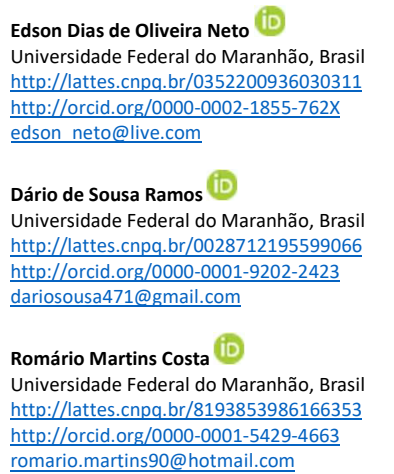

Raissa Rachel Salustriano da Silva Matos (iD Universidade Federal do Maranhão, Brasil http://lattes.cnpq.br/0720581765268326 http://orcid.org/0000-0002-8908-2297 raissasalustriano@yahoo.com.br

\section{Referencing this:}

BARROSO, V. B.; PACHÊCO, M. B.; MORAES, L. F.; MOURA, M. S.; PEREIRA, R. Y. F.; CONCEIÇÃO, A. O.; OLIVEIRA NETO, E. D.; RAMOS, D. S.; COSTA, R. M.; MATOS, R. R. S. S.. Produção de Zínnia elegans em substratos a base de bagana de carnaúba. Revista Ibero Americana de Ciências Ambientais, v.11, n.7, p.153-160, 2020. DOI: http://doi.org/10.6008/CBPC2179-6858.2020.007.0014 


\section{INTRODUÇÃO}

A Zinnia elegans Jacq. (Zínia) também conhecida como capitão, moça e velha ou canela-de-velho é uma angiosperma de ciclo anual pertencente à família Asteraceae, apresentando flores do tipo margarida simples, dobrado ou crespo, adequada para o cultivo em vasos destinados a ornamentação e usada na composição de paisagismo, além disso, pode ser cultivada em períodos distintos no decorrer do ano (IQBAL et al., 2012; AHMAD et al., 2015).

O cultivo de flores com o passar dos anos tem crescido e ganhado espaço no mercado agrícola, requisitos como a diversidade são necessários para uma maior produção, e com isso introduzir novas plantas ornamentais no mercado. As zínias são plantas ornamentais de grande importância no mercado mundial de flores por serem não casuais, apresentando uma forma de originalidade, despertam a curiosidade e o interesse, estimulando o seu consumo (PALLAVI et al., 2017).

Com o desenvolvimento populacional crescendo, a população está cada vez mais consumindo e gerando resíduos em grande quantidade, sendo que muitos desses resíduos podem ser reciclados e/ou reutilizados em outras atividades da indústria ou agropecuária, o que promove melhoria ao meio ambiente e preservação dos recursos naturais (COSTA et al., 2017). Tem se tornado cada vez mais comum a realização de pesquisas visando a reutilização desses resíduos na atividade agrícola, sendo que muitas já comprovaram o êxito na utilização desses resíduos na produção de mudas de frutíferas, olerícolas e floríferas (CRUZ et al., 2018; OLIVEIRA et al., 2019; PEREIRA et al., 2019; FERREIRA et al., 2020).

As características físico-químicas dos substratos como a porosidade o $\mathrm{pH}$ e a densidade afetam diretamente o crescimento e desenvolvimento radicular das plantas. Em vista disso, os substratos utilizados na produção orgânica contêm nutrientes que facilita o seu desenvolvimento inicial, são de baixo custo e de fácil aquisição (MORAES et al., 2016).

A bagana de carnaúba é resíduo obtido após o processo de extração da cera da palha da palmeira Copernicia prunifera (Mill.) H.E. Moore., e pode ser encontrada em grandes proporções em propriedades rurais (FERREIRA et al., 2013).

Diante da demanda por substratos de baixo custo, de boa qualidade e que possa aumentar a produção de plantas ornamentais e da possibilidade de reaproveitamento da grande quantidade de materiais disponíveis na região, surge a necessidade de avaliar o uso da bagana de carnaúba na produção de flores. Assim, objetivou-se com presente trabalho avaliar a produção de mudas de Zinnia elegans Jacq. em substratos a base de bagana de carnaúba.

\section{MATERIAIS E MÉTODOS}

O experimento foi conduzido no período de abril a junho de 2019 em casa de vegetação com luminosidade de 70\%, no Centro de Ciências Agrárias e Ambientais (CCAA) da Universidade Federal do Maranhão (UFMA) (0344'17" S e 4320’29” W e altitude de $107 \mathrm{~m}$ ), localizado no município de Chapadinha/MA. O clima da região é classificado como tropical úmido (SELBACH et al., 2008), com totais 
pluviométricos anuais que variam de 1.600 a 2.000 mm (NOGUEIRA et al., 2012) e temperatura média anual superior a $27^{\circ} \mathrm{C}$ (PASSOS et al., 2016).

O trabalho foi conduzido em delineamento inteiramente casualizado, com 5 tratamentos de substratos formulados a base de bagana de carnaúba nas proporções de 0, 20, 40, 60, 80 e 100\%, acrescido de solo. O solo utilizado foi classificado como Latossolo Amarelo distrófico (LAd) (SANTOS et al., 2018).

A avaliação biométrica as mudas de Zinnia elegans Jacq. foi realizada aos 60 dias após a semeadura. Foram quantificadas as seguintes variáveis: inflorescência (IN), número de folhas (NF); altura das plantas (AP) em $\mathrm{cm}$, foi obtida com uso de régua graduada; diâmetro do caule (DC) em $\mathrm{mm}$, foi mesurado através de paquímetro digital (Digimess ${ }^{\circledR}$ ) ao nível do substrato; comprimento radicular (CR) em cm, mensurado com auxílio de uma régua graduada; volume radicular (VR) em, determinado pelo método da proveta graduada; massa fresca da raiz (MFR) e massa fresca parte aérea (MFPA); massa seca de raiz (MSR) e massa seca parte aérea (MSPA) obtidos pelo método da secagem em estufa com circulação forçada de ar e pesadas em balança semi-analítica com precisão de 0,01 g; e índice de qualidade Dickson (IQD) conforme formula de Dickson et al. (1960).

A análise de granulometria do solo constatou que o mesmo possui: $384 \mathrm{~g}$ areia grossa $\mathrm{kg}^{-1} ; 336 \mathrm{~g}$ areia fina $\mathrm{kg}^{-1} ; 112 \mathrm{~g}$ de silte $\mathrm{kg}^{-1} ; 168 \mathrm{~g}$ de argila total $\mathrm{kg}^{-1} ; 38 \mathrm{~g}$ de argila natural $\mathrm{kg}^{-1}$; textura Franco arenosa; e grau de floculação de $0,77 \mathrm{~kg} \mathrm{~kg}^{-1}$. Foram realizadas as caracterizações física (Tabela 1) e química (Tabela 2) dos substratos. Para a caracterização física foram realizadas análises de densidade global, densidade de partícula e porosidade, determinados conforme procedimentos descritos por Schmitz et al. (2002).

Tabela 1: Densidade global (DG), densidade de partícula (DP) e porosidade (P), dos substratos à base de bagana de carnaúba (BC), acrescidos de solo.

\begin{tabular}{llll}
\hline Substratos & DG & DP & $\begin{array}{l}P \\
\%\end{array}$ \\
\cline { 2 - 3 } & & & 51,53 \\
$0 \% \mathrm{BC}$ & 1,28 & 2,64 & 55,33 \\
$40 \% \mathrm{BC}$ & 1,17 & 2,61 & 59,26 \\
$60 \% \mathrm{BC}$ & 0,99 & 2,42 & 60,78 \\
$80 \% \mathrm{BC}$ & 0,78 & 1,98 & 68,53 \\
$100 \% \mathrm{BC}$ & 0,56 & 1,77 & 70,20 \\
\hline
\end{tabular}

Tabela 2: Valores de $\mathrm{pH}$, matéria orgânica (M.O.) e teores totais de nitrogênio $(\mathrm{N})$, fosforo (P), potássio (K), cálcio (Ca), magnésio $(\mathrm{Mg})$ e enxofre $(\mathrm{S})$ dos substratos à base de bagana de carnaúba (BC), acrescidos de solo.

\begin{tabular}{|c|c|c|c|c|c|c|c|c|}
\hline Substrato & $\mathrm{pH}$ & $\begin{array}{l}\text { M.O. } \\
\text { g kg-1 }^{-1}\end{array}$ & $\begin{array}{l}\mathrm{N} \\
\mathrm{g} \mathrm{kg}^{-1}\end{array}$ & $\begin{array}{l}\mathrm{P} \\
\mathrm{mg} \mathrm{kg}^{-1}\end{array}$ & $\mathrm{~K}$ & $\begin{array}{l}\mathrm{Ca} \\
\mathrm{ol}_{\mathrm{c}} \mathrm{kg}^{-1}\end{array}$ & $\mathrm{Mg}$ & $S$ \\
\hline $0 \% \mathrm{BC}$ & 4,0 & 0,61 & 1,23 & 14 & 0,67 & 1,60 & 1,00 & 3,8 \\
\hline $20 \%$ BC & 5,1 & 60,67 & 3,92 & 6 & 0,63 & 2,90 & 0,50 & 4,3 \\
\hline $40 \% \mathrm{BC}$ & 4,9 & 73,82 & 5,36 & 12 & 0,72 & 4,50 & 1,30 & 6,8 \\
\hline $60 \% \mathrm{BC}$ & 5,0 & 95,22 & 6,89 & 23 & 1,28 & 5,90 & 1,40 & 8,9 \\
\hline $80 \%$ BC & 5,1 & 114,26 & 9,28 & 42 & 2,21 & 7,00 & 3,10 & 12,7 \\
\hline $100 \% \mathrm{BC}$ & 5,3 & 598,86 & 4,02 & 89 & 3,88 & 19,80 & 10,40 & 34,6 \\
\hline
\end{tabular}

A bagana de carnaúba foi obtida na zona rural do município de Chapadinha e foi esmagada mecanicamente com o auxílio de picador de forragem conforme a metodologia utilizada por Oliveira et al. (2020), posteriormente, a bagana foi peneirada com peneira de $8 \mathrm{~mm}$ para remover qualquer material que pudesse interferir nos resultados e padronizar a granulometria da bagana para facilitar a homogeneização 
do substrato. O solo também passou pelo processo de peneiramento com peneira de $8 \mathrm{~mm}$ para retirada de galhos, folhas e pedregosidade afim de facilitar a homogeneização do substrato.

Os dados obtidos foram submetidos à análise de variância (ANOVA) pelo teste $\mathrm{F}$ ao nível de $5 \%$ de significância para diagnóstico de efeito significativo com o auxílio do software Infostat ${ }^{\circledR}$ versão 2015 (RIENZO et al., 2011). Quando houve efeito significativo dos substratos, procedeu-se a análise de regressão (BANZATTO et al., 1992).

\section{RESULTADOS}

Através da análise de variância observou-se que os substratos com proporções de BC entre $40 \%$ e $60 \%$ proporcionaram os melhores resultados para mudas de zinia. Esses resultados indicam a importância do teor de nutrientes presente no substrato para o crescimento e desenvolvimento da cultura. Verificou-se que houve diferença significativa $(p<0,05)$ para as variáveis altura da planta (AP), volume radicular $(V R)$, massa fresca da parte aérea (MFPA), massa fresca radicular (MFR). No entanto, não houve significância $(p>0,05)$ para as variáveis número de folhas (NF), diâmetro do caule (DC), comprimento radicular (CR), massa seca da parte aérea (MSPA), massa seca radicular (MSR), inflorescência (IN), índice de qualidade de Dickson (IQD) (Tabela 3).

Tabela 3: Resumo da análise de variância do número de folhas (NF), altura da planta (AP), diâmetro do caule (DC), comprimento radicular (CR), volume radicular (VR), massa fresca da parte aérea (MFPA), massa fresa radicular (MFR), massa seca da parte aérea (MSPA), massa seca radicular (MSR), inflorescência (IN) e e índice de qualidade Dickson (IQD) em função de proporções de bagana de carnaúba acrescidos de solo.

\begin{tabular}{llllllllllll} 
Tratamentos & NF & AP & DC & CR & VR & MSPA & MSR & MFPA & MFR & IN & IQD \\
\hline F & $1,59^{\text {ns }}$ & $9,24^{*}$ & $2,72^{\text {ns }}$ & $0,79^{\text {ns }}$ & $3,53^{*}$ & $2,12^{\text {ns }}$ & $0,71^{\text {ns }}$ & $10,99^{*}$ & $4,20^{*}$ & $1,44^{\text {ns }}$ & $0,51^{\text {ns }}$ \\
CV(\%) & 55,5 & 23,3 & 29,1 & 190 & 54,3 & 61,1 & 95,15 & 35,43 & 65,8 & 58,9 & 16,68 \\
\hline
\end{tabular}

*: Significativo ao nível de $5 \%$ de probabilidade, pelo teste Duncan $(p<0,05) ;{ }^{\text {ns }}$ : não significativo $(p>0,05)$; CV: coeficiente de variação.

Na Figura 1, observa-se que a altura da planta (AP) se ajustou ao modelo de regressão quadrático. Percebe-se que há um incremento da AP à medida que a concentração de BC aumenta no substrato até a concentração de $57,19 \%$, onde começa a decair. Foi obtido uma altura de 58,99 cm com a concentração de $57,19 \%$ de $B C$ na composição do substrato.

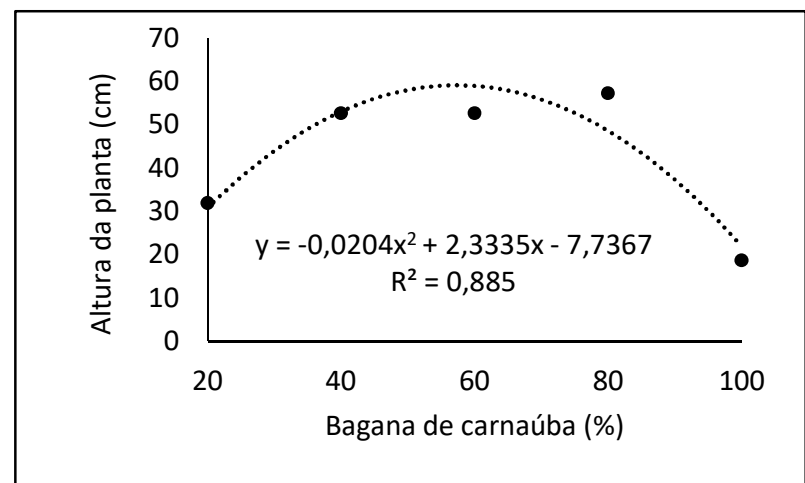

Figura 1: Altura da planta de zínia em função de substratos a base de bagana de carnaúba, acrescidos de solo.

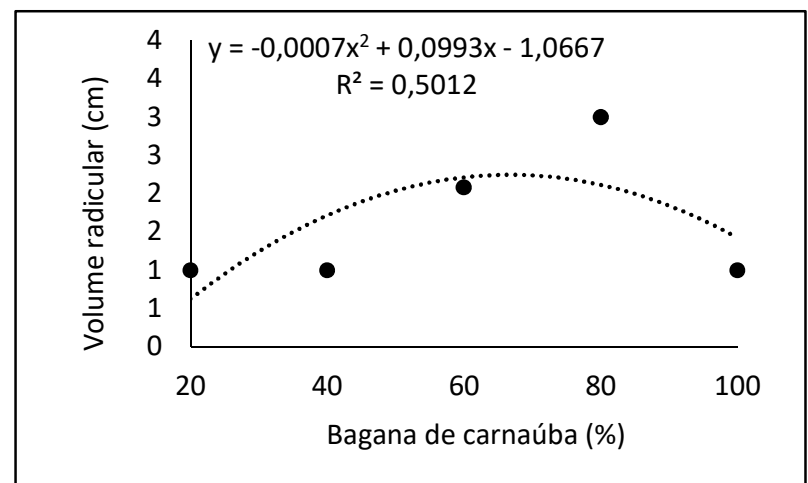

Figura 2: Volume radicular de mudas de zínia em função de substratos a base de bagana de carnaúba, acrescidos de solo. 
O volume radicular (VR) ajustou-se ao modelo de regressão quadrático. Assim como a AP, o VR também registrou um incremento à medida que a concentração de $\mathrm{BC}$ aumentava no substrato, chegando a registrar o melhor valor $\left(2,54 \mathrm{~cm}^{3}\right)$ com a concentração de $70,92 \%$ de bagana no substrato (Figura 2). 0 cultivo em recipientes com substrato distingue-se do cultivo em solo principalmente pela área limitada para o desenvolvimento das raízes.

A variável massa fresca radicular (MFR) se ajustou ao modelo de regressão quadrático. A MFR também registrou um incremento à medida que o teor de $\mathrm{BC}$ aumentava no substrato até a concentração de $66,81 \%$, onde a partir daí começou a declinar a MFR. O melhor valor foi obtido com a concentração de $66,81 \%$ com a massa de 2,4 g (Figura 3).

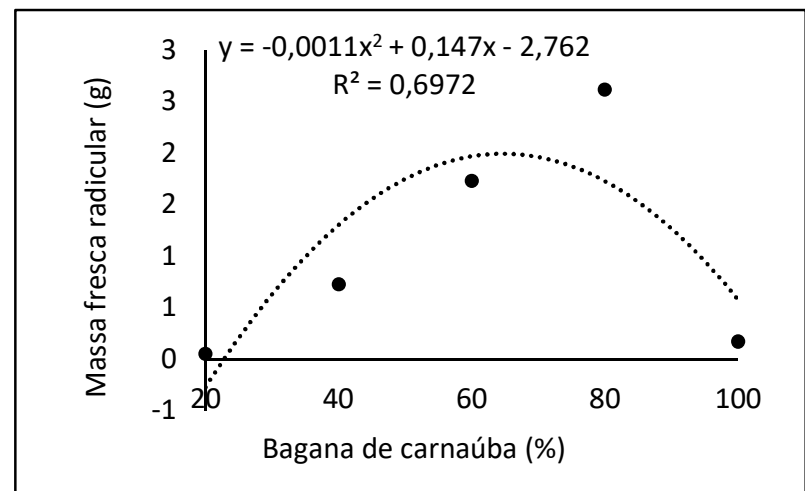

Figura 3: Massa fresca radicular de mudas de zínia em função de substratos a base de bagana de carnaúba, acrescidos de solo.

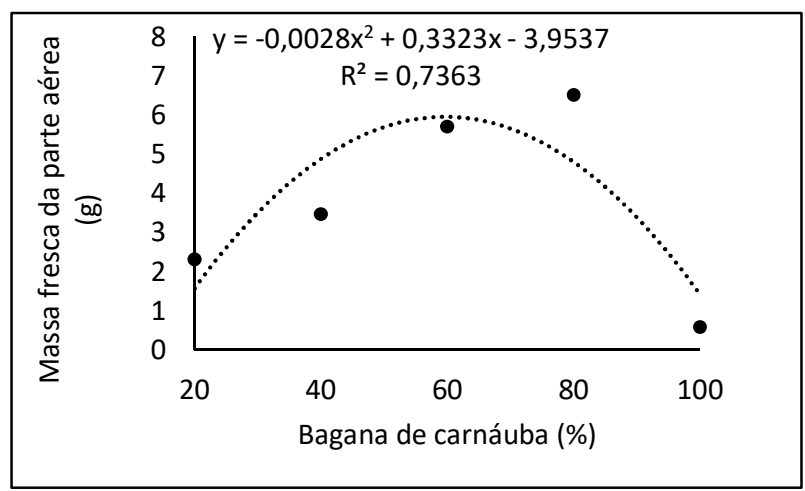

Figura 4: Massa fresca parte aérea de mudas de zínia em função de substratos a base de bagana de carnaúba, acrescidos de solo.

A massa fresca da parte aérea (MFPA) ajustou-se ao modelo de regressão quadrático. A medida que se eleva a porcentagem de BC no substrato, há um incremento no valor da MFPA até a proporção de 59,33\% de $\mathrm{BC}$, onde é obtido o valor máximo de 5,90 g (Figura 4).

\section{DISCUSSÃO}

De acordo com os resultados encontrados em Pêgo et al. (2019), o pH não influencia tanto o desenvolvimento da zinia, uma vez que esta espécie consegue se desenvolver em substratos que apresentam um pH alto (em torno de 8,0) ou pH baixo $(5,0)$. Kämpf et al. (2000) afirmam que o pH ideal para substratos é de 5,0 a 5,8, sendo que os valores de pH dos substratos utilizados atendem essa exigência (Tabela 2), portanto, as mudas de zinia conseguiram ter um ótimo desenvolvimento. Possivelmente a diferença entre os tratamentos foi gerada pela concentração de BC, por meio da modificação da estrutura do substrato e da liberação de nutrientes com a decomposição da BC.

Sousa et al. (2011) também verificaram um incremento na AP quando utilizada a BC na composição do substrato, inclusive com altura de planta similar ao substrato comercial.

Segundo Costa et al. (2017), materiais com baixa porosidade podem demonstrar problemas de trocas gasosas das raízes, tendo um efeito negativo na movimentação de água e drenagem, e consequentemente, menor desenvolvimento radicular das plantas. Em contrapartida, misturas com porosidade mais elevada 
podem ser vantajosas para uma aeração do sistema radicular. No presente trabalho, as porosidades encontradas nos substratos são consideradas adequadas ou até elevadas (Tabela 1). Essa porosidade provavelmente possibilitou o desenvolvimento do VR (Figura 2).

Araújo et al. (2017) encontraram resultados onde a BC apresentou uma melhora significativa para mudas de Schizolobium amazonicum Huber ex Ducke. De acordo com os autores, esse resultado positivo se deu pelo aumento da fertilidade e melhoria das propriedades físicas do substrato, aumentando o desenvolvimento da muda, tanto radicular como da parte aérea. Resultados semelhantes foram observados na AP (Figura 1), sendo que a incorporação de BC promoveu o crescimento da muda, possivelmente em função da melhoria das qualidades físicas e da liberação de nutrientes essenciais a planta. Entretanto, a BC é um material pouco utilizado na produção de mudas, apesar do resíduo de carnaúba ser encontrado em abundancia em muitas regiões do país, principalmente na sub-região Meio Norte brasileiro.

Segundo Meirelles et al. (2017), substratos que contenham altos teores de matéria orgânica, favorecem a formação de raízes laterais nas plantas, promovendo o aumento da atividade radicular, tornando-as mais eficientes no transporte de nutrientes. O VR e a MFR demonstram isso de forma clara, pois a adição de $\mathrm{BC}$ promoveu o desenvolvimento do sistema radicular por meio da liberação de raízes laterais que aumentou o VR e a deposição de biomassa nas raízes (Figuras 3 e 4).

De acordo com Pêgo et al. (2011), mudas que apresentam alta qualidade fisiológica também proporcionam maior translocação de reservas dos cotilédones para o eixo embrionário durante seu processo de germinação, possibilitando um maior potencial para o crescimento de plântulas, consequentemente maior percentual de produção.

De acordo com Caldeira et al. (2008), a MFPA e MFR devem terá proporção 2:1. No entanto, a proporção observada no presente trabalho foi bem maior, chegando a ter uma proporção de 5:1 para (Figura 3). Podendo analisar a relação entre ambos antes de ir para o campo, onde a parte aérea não podendo ser maior que o sistema radicular das mudas, por apresentar problemas seguinte como absorção de água.

Lustosa Filho et al. (2015), ressalta a importância do resíduo orgânico na produção de mudas e que a eficiência é até superior em relação a outras substâncias minerais utilizadas na sua produção, substância chamada triacontanol, presente na cera de carnaúba da qual a bagana é o resíduo.

Diante desses resultados, é evidente o potencial da BC para a produção de mudas de inúmeras espécies frutíferas e floríferas. A produção de mudas de zinia utilizando BC é uma alternativa viável ao descarte incorreto desse material no meio ambiente. Entretanto, torna-se crucial o desenvolvimento de mais pesquisas utilizando a $B C$ na produção de mudas de outras espécies, afim de promover o desenvolvimento de uma agricultura cada vez mais sustentável, além de possibilitar o progresso da produção de mudas no Estado do Maranhão, o que dará suporte para o desenvolvimento de outros setores agrícolas.

\section{CONCLUSÕES}

Substratos a base de bagana de carnaúba demonstram bons resultados para a produção de mudas 
de zínia, podendo ser utilizado na produção de outras espécies floríferas. Recomenda-se a utilização do uso de $40 \%$ bagana de carnaúba + solo para produção de mudas de Zinnia elegans Jacq., pois essa proporção de bagana apresenta disponibilidade de nutrientes e características físicas que favorecem o desenvolvimento das mudas.

\section{REFERÊNCIAS}

AHMAD, I.; WHIPKER, B. E.; DOLE, J. M.. Paclobutrazol or ancymidol effects on postharvest performance of potted ornamental plants and plugs. Hortscience, v.50, n.9, p.13701374, 2015.

DOI: http://doi.org/10.21273/HORTSCI.50.9.1370

ARAÚJO, E. F.; AGUIAR, A. S.; ARAUCO, M. A. S.; GONÇALVES, E. O.; ALMEIDA, K. N. S.. Crescimento e qualidade de mudas de Paricá produzidas em substratos à base de resíduos orgânicos. Nativa, Sinop, v.5, n.1, p.16-23, 2017. DOI: http://doi.org/10.5935/2318-7670.v05n01a03

BANZATTO, D. A.; KRONKA, S. N.. Experimentação agrícola. Jaboticabal: FUNEP, 1992.

CALDEIRA, M. V. W.; ROSA, G. N.; FENILLI, T. A. B.; HARBS, R. M. P.. Composto orgânico na produção de mudas de aroeiravermelha. Scientia Agraria, v.9, n.1, p.27-33, 2008. DOI: http://dx.doi.org/10.5380/rsa.v9i1.9898

COSTA, J. C. F.; MENDONÇA, R. M. N.; FERNANDES, L. F.; OLIVEIRA, F. P.; SANTOS, D.. Caracterização física de substratos orgânicos para o enraizamento de estacas de goiabeira. Revista Brasileira de Agropecuária Sustentável, v.7, n.2, p.90-96, 2017. DOI:

http://doi.org/10.21206/rbas.v7i2.390

CRUZ, A. C.; LIMA, J. S.; ANDRADE, H. A. F.; OLIVEIRA, A. R. F.; MILK, M. R. L.; SANTOS, L. R.; SILVA, T. F.; GONDIM, M. M. S.; MACHADO, N. A. F.; SILVA-MATOS, R. R. S.. Stalk decomposed babassu for production of seedlings of Bougainvillea spectabilis Willd in different levels of indolebutyric acid. Asian Academic Research Journal of Multidisciplinary, v.5, n.1, p.98-107, 2018.

DICKSON, A.; LEAF, A. L.; HOSNER, J. F.. Quality appraisal of white spruce and white pine seedling stock in nurseries. The Forest Chronicle, Ottawa, v.36, p.10-13, 1960.

RIENZO, J. A.; CASANOVES, F.; BALZARINI, M. G.; GONZALES, L.; TABLADA, M.; ROBLEDO, C. W.. Infostat verion 2011. Grupo InFostat, Faculdade de Ciências Agropecuárias, Universidad Nacional de Córdoba, Buenos Aires, v.8, p.195199, 2011.

FERREIRA, C. S.; NUNES, J. A. R.; GOMES, R. L. F.. Manejo de corte das folhas de Copernicia prunifera (Miller) H. E. Moore no Piauí. Revista Caatinga, Mossoró, v.26, n.2, p.25-30, 2013.

FERREIRA, M. V. N.; PEREIRA, R. Y. F.; SILVA, R. O.; DOIHARA, I. P.. Resíduo de café e casca de ovo na produção de mudas de quiabo (Abelmoschus esculentus (L.) Moench). Global Science and Technology, Rio Verde, v.13, n.2, p.169-185, 2020.
IQBAL, D.; HABIB, U.; ABBASI, NA.; CHAUDHRY, A. N.. Improvement in postharvest attributes of zinnia (Zinnia elegans cv. Benary's giant) cut-flowers by the application of various growth regulators. Pakistan Journal of Botânica, v.44, n.3, p.1091-1094, 2012.

KÄMPF, A. N.; FERMINO, M. H.. Substratos para plantas: a base da produção vegetal em recipientes. Porto Alegre: Genesis, 2000.

LUSTOSA FILHO, J. F.; NÓBREGA, J. C. A.; NÓBREGA, R. S. A.; DIAS, B. O.; AMARAL, F. H. C.; AMORIM, S. P. N.. Influence of organic substrates on growth and nutrient contents of jatobá (Hymenaea stigonocarpa). African Journal of Agricultural Research, v.10, n.26, p.2544-2552, 2015. DOI: http://doi.org/10.5897/AJAR2015.9781

MEIRELLES, A. F. M.; BALDOTTO M. A.; BALDOTTO L. E. B.. Produtividade da alface (Lactuca sativa $\mathrm{L}$.) em resposta à aplicação de ácidos húmicos e bactérias diazotróficas, em condições de campo. Revista Ceres, v.64, n.5, p.553-556, 2017. DOI: https://doi.org/10.1590/0034737x201764050014

MORAES, E. R.; SANTANA, A. S.; PEIXOTO, J. V. M.; SILVA, R. R.. Use of alternative waste wood substrates in the production of seedlings zinnia. African Journal of Agricultural Research, v.11, n.33, p.3090-3096, 2016. DOI: http://doi.org/10.5897/AJAR2016.11305

NOGUEIRA, V. F. B.; CORREIA, M. F.; NOGUEIRA, V. S.. Impacto do plantio de soja e do Oceano Pacífico Equatorial na precipitação e temperatura na cidade de ChapadinhaMA. Revista Brasileira de Geografia Física, v.5, n.3, p.708724, 2012. DOI: https://doi.org/10.26848/rbgf.v5.3.p708$\underline{724}$

OLIVEIRA, P. S. T.; CARNEIRO, C. A. M.; PEREIRA, R. Y. F.; ANDRADE, H. A. F.; SILVA-MATOS, R. R. S.. Produção de mudas de açaizeiro em substratos a base de caule decomposto de babaçu. Agrarian Academy, Goiânia, v.6, n.11, p.272-280, 2019. DOI:

http://doi.org/10.18677/Agrarian Academy 2019a26

OLIVEIRA, P. S. T.; SILVA, F. L. S.; CORDEIRO, K. V.; SOUSA, G. S.; NUNES, R. L. S.; PEREIRA, R. Y. F.; ALBANO-MACHADO, F. G.; OLIVEIRA, M. M. T.; SILVA-MATOS, R. R. S.. Efficacy of substrate and humic substance on cuttings production of Spondia purpurea L. Research, Society and Development, v.9, n.8, p.e60985006, 2020. DOI:

http://dx.doi.org/10.33448/rsd-v9i8.5006

PALLAVI, B.; NIVAS, S. K.; D 'SOUZA, L.; GANAPATHI, T. R.; HEDGE, S.. Gamma rays induced variations in seed germination, growth and phenotypic characteristics of Zinnia elegans var. Dremland. Advances In Horticultural Science. 
v.31, n.4, p.267-273, 2017. DOI:

http://doi.org/10.13128/ahs-20289

PASSOS, M. L. V.; ZAMBRZYCKI, G. C.; PEREIRA, R. S.. Balanço hídrico e classificação climática para uma determinada região de Chapadinha/MA. Revista Brasileira de Agricultura Irrigada, v.10, n.4, p.758-766, 2016. DOI:

http://doi.org/10.7127/rbai.v10n400402

PÊGO, R. G.; ANTUNES, L. F. S.; SILVA, A. R. C.. Vigor of zinnia seedlings produced in alternative substrate in trays with different cell. Ornamental Horticulture, v.25, n.4, p.417-424, 2019. DOI: http://doi.org/10.1590/2447-536x.v25i4.2049

PÊGO, R. G.; NUNES, U. R.; MASSAD, M. D.. Qualidade fisiológica de sementes e desempenho de plantas de rúcula no campo. Ciência Rural, v.41, n.8, p.1341-1346, 2011. DOI: http://doi.org/10.1590/S0103-84782011000800008

PEREIRA, R. Y. F.; MORAIS, S. F.; OLIVEIRA, P. S. T.; NUNES, R. L. S.; SANTANA, M. S.; ALBANO, F. G.; SILVAMATOS, R. R. S.. Substratos alternativos para produção de mudas de maracujazeiro em Chapadinha/MA. In: SILVA-MATOS, R. R. S; FURTADO, M. B.; FARIAS, M. F.. Tecnologia de produção em fruticultura. Ponta Grossa: Atena, 2019. p.48-59. DOI: http://dx.doi.org/10.22533/at.ed.0311909106

SANTOS, H. G.; JACOMINE, P. K. T.; ANJOS, L. H. C.; OLIVEIRA, V. A.; COELHO, M. R.; LUMBRERAS, J. F.; ALMEIDA, J. A.; CUNHA, T. J. F.; OLIVEIRA, J. B.. Sistema Brasileiro de Classificação de Solos. Brasília: Embrapa, 2018.

SCHMITZ, J. A. K.; SOUZA, P. V. D.; KAMPF, A. N..

Propriedades químicas e físicas de substratos de origem mineral e orgânica para o cultivo de mudas em recipientes. Ciência Rural, v.32, n.6, p.937-944, 2002. DOI: http://doi.org/10.1590/S0103-84782002000600005

SELBACH, J. F.; LEITE, J. R. S. A.. Environment in Lower Parnaíba: eyes in the world, feet in the region. São Luís: EDUFMA, 2008.

SOUSA, H. H. F.; BEZERRA, F. C.; ASSIS JÚNIOR, R. N.; FERREIRA, F. V. M.; SILVA, T. C.; CRISÓSTOMO, L. A.. Produção de mudas de Zinia elegans em substratos à base de resíduos agroindustriais e agropecuários em diferentes tamanhos de recipientes. Revista Brasileira de Horticultura Ornamental, v.17, n.2, p.115-120, 2011. DOI: http://doi.org/10.14295/rbho.v17i2.706

A CBPC - Companhia Brasileira de Produção Científica (CNPJ: 11.221.422/0001-03) detém os direitos materiais desta publicação. Os direitos referem-se à publicação do trabalho em qualquer parte do mundo, incluindo os direitos às renovações, expansões e disseminações da contribuição, bem como outros direitos subsidiários. Todos os trabalhos publicados eletronicamente poderão posteriormente ser publicados em coletâneas impressas sob coordenação da Sustenere Publishing, da Companhia Brasileira de Produção Científica e seus parceiros autorizados. Os (as) autores (as) preservam os direitos autorais, mas não têm permissão para a publicação da contribuição em outro meio, impresso ou digital, em português ou em tradução. 